\title{
Normative Grip Strength Values in Males and Females, ages 50 to 89 years old
}

James R. Roush

A. T. Still University of Health Sciences, jroush@atsu.edu

Kaylee L. Gombold

A. T. Still University of Health Sciences, kgombold@atsu.edu

R. Curtis Bay

A. T. Still University of Health Sciences, cbay@atsu.edu

Follow this and additional works at: https://nsuworks.nova.edu/ijahsp

Part of the Physical Therapy Commons

\section{Recommended Citation}

Roush JR, Gombold KL, Bay RC. Normative Grip Strength Values in Males and Females, ages 50 to 89 years old. The Internet Journal of Allied Health Sciences and Practice. 2018 Jan 01;16(1), Article 7.

This Manuscript is brought to you for free and open access by the College of Health Care Sciences at NSUWorks. It has been accepted for inclusion in Internet Journal of Allied Health Sciences and Practice by an authorized editor of NSUWorks. For more information, please contact nsuworks@nova.edu. 


\title{
Normative Grip Strength Values in Males and Females, ages 50 to 89 years old
}

\begin{abstract}
Purpose. To develop normative reference values for grip strength of males and females between the ages of 50 and 89 years old that can be used by health care professionals in clinical settings.

Methods. This study assessed data from a sample of males and females between the ages of 50 and 89 years old who participated in the Health and Retirement Study (HRS) sponsored by the National Institute on Aging. The Health and Retirement Study collected data from 6,266 participants in a physical measures substudy. Grip strength was assessed in a standing position with the shoulder adducted and elbow flexed to 90 degrees. One practice trial was allowed and then the participant performed 2 maximal effort trials using each hand. Right and left hand mean scores were calculated. The HRS data were reported in kilograms.

Results. Subjects were stratified by sex and age. Each stratum was defined using 5-year intervals, male or female, and by right or left hand. Mean grip strength, standard deviation, sample size, and percentile ranks from 5 to 95 at intervals of 5 are reported for each stratum in both kilograms and pounds.

Conclusion. The normative values provided in this report should advance the clinical utility of grip strength as a physical measure. Percentile ranks are easy to determine and interpret for both the patient and clinician. Clinicians will benefit from the results of this study by better assessing the physical status of their patients, developing better goals for their patients, and providing better education to their patients on this aspect of physical health.
\end{abstract}

\section{Author Bio(s)}

James R. Roush, PT, PhD, ATC is a professor in the Physical Therapy Program at A. T. Still University of Health Sciences. Kaylee Gombold, PT, DPT, is a physical therapist in Minnesota. R. Curtis Bay, PhD, is a professor of Statistics in the Department of Interdisciplinary Studies at A. T. Still University of Health Sciences. 


\title{
IJAHSP \\ The Internet Joưnal of Allied Health Sciences and Practice
}

Dedicated to allied health professional practice and education

Vol. 16 No. 1 ISSN 1540-580X

\section{Normative Grip Strength Values in Men and Women, Ages 50 to 89 Years' Old}

\author{
James R. Roush, PT, PhD, ATC \\ Kaylee L. Gombold, PT, DPT \\ R. Curtis Bay, PhD
}

A. T. Still University

United States

\begin{abstract}
Purpose. The purpose was to develop normative reference values for grip strength of men and women between the ages of 50 and 89 years old that can be used by health care professionals in clinical settings. Methods. Data were analyzed from a sample of men and women between the ages of 50 and 89 years old who participated in the Health and Retirement Study (HRS) sponsored by the National Institute on Aging. Data collected from the Health and Retirement Study included 6,266 participants in a physical measures sub-study. Grip strength was assessed in a standing position with the shoulder adducted and elbow flexed to $90^{\circ}$. One practice trial was allowed and then the participant performed 2 maximal-effort trials using each hand. Right and left hand mean scores were calculated. The HRS data were reported in kilograms. Results. Subjects were stratified by sex and age. Each stratum was defined using five-year intervals, male or female sex, and right or left handedness. Mean grip strength, standard deviation, sample size, and percentile ranks from 5 to 95 at intervals of 5 were reported for each stratum in both kilograms and pounds. Conclusion. The normative values that were used in this report should advance the clinical utility of grip strength as a physical measure. Percentile ranks are easy to determine and interpret for both the patient and clinician. Clinicians will benefit from the results of this study by better assessing the physical status of their patients, developing better goals for their patients, and providing better education to their patients on this aspect of physical health.
\end{abstract}

\section{INTRODUCTION}

The hand performs many important functions, but its most distinctive trait is the ability to grip. During the aging process, many changes result in muscle weakness. These changes are associated with various morbidities. Gale et al reported that grip strength was a long-term predictor of mortality from all causes in men while Rantanen et al found that grip strength was strongly associated with impending mortality in older, disabled women.1,2 Simmons et al found a negative correlation between grip strength and probability of hospital admission. ${ }^{3}$ Leong et al noted that grip strength was more strongly predictive of mortality than systolic blood pressure. 4

Grip strength measurements are used to provide clinicians with an indication of overall health, but interpretation of these data requires valid reference values so that patient measurements can be compared to age- and sex-specific normative data. The reference values for grip strength that are typically used in a clinical setting were developed by Mathiowetz et al in 1985.5 These values are based on a convenience sample of 310 male and 318 female participants, ranging in age from 20 to 94 years. The derived normative values were based on fewer than 30 subjects on average in each stratum. Little research has followed to help establish more robust normative values for grip strength. Clinicians have had little choice but to rely on Mathiowetz's normative values and have routinely accepted them as part of their practice.

During 2008, the Health and Retirement Study (HRS), sponsored by the National Institute on Aging, was used to collect data on various functional measures, including balance tests, walking speed, and grip strength from 6,266 individuals between the ages of 50 and 89. The Institute of Social Research at the University of Michigan 6 conducted the study. The HRS was a longitudinal study of the economic, health, marital, and family status of older Americans in different living environments and different locations in the 
United States. ${ }^{6}$ Normative values of grip strength for men and women at various ages may be calculated from these data. The purpose of this study was to establish clinical normative values, including percentile ranks for men and women between the ages of 50 and 89 years based on data collected in 2008 through the HRS.

\section{METHODS}

\section{Data}

Data for this project were acquired from HRS as a subset of data collected in 2008 from 6,266 participants. The Institutional Review Board for A. T. Still University of Health Sciences determined that this project was exempt from continuing review.

\section{Data Collection Procedures}

The HRS used testers trained to collect grip strength measurements using the Smedley spring-type, hand-held dynamometer (Scandidact, Denmark). The Smedley dynamometer records measurements to the nearest $0.5 \mathrm{~kg}$ of force. Guerra and Amaral reported that the Pearson correlation between forces recorded with the Smedley dynamometer and known forces was .98. ${ }^{7}$

Prior to dynamometer adjustment, participants provided consent to the HRS tester and confirmed that they had not had surgery, swelling, inflammation, severe pain, or injury in either of their hands in the past 6 months. After participants consented to the study, the tester adjusted the dynamometer for the individual's hand size. The lining of the bottom handle of the dynamometer was adjusted to the metacarpophalangeal joints, and the upper handle was adjusted to the second phalanx just above the interphalangeal joints of the index and little fingers. Subjects were placed in a standing position with the shoulder adducted and elbow flexed to $90^{\circ}$. Sitting and lying down were permitted if the subject was unable to assume the standing test position.

Participants were instructed to provide a maximal effort for several seconds and then release their grip. They were allowed to practice one time, and then the measurements were collected, using two trials from the right hand and two trials from the left hand. The average of the two trials for each hand was calculated.

\section{Analyses}

Data were weighted to account for differential probability in the selection process and nonresponse from potential participants, according to weights provided by HRS in order to accurately reflect the national population. Average grip strengths for the right and left hands and age and sex of participants were abstracted from the dataset.

Participants were stratified into 8 groups for each sex using an age interval of 5 years from 50 years to 89 years of age. Means and standard deviations for grip strength were calculated for age (50 to 54 years, 55 to 59 years, 60 to 64 years, 65 to 69 years, 70 to 74 years, 75 to 79 years, 80 to 84 years, and 85 to 89 years) and sex (male or female). Sample size for each of these strata was also calculated to assess the precision of our estimates. The goal was to estimate mean grip strength at a $99 \%$ confidence level and a margin of error of \pm 5 pounds so that we would be $99 \%$ certain that the true population mean ranges from between 5 pounds lower and 5 pounds higher than the mean we obtained from the HRS survey. IBM SPSS 23 and Microsoft Excel statistical packages were used for all calculations. ${ }^{8}$ Data from the original HRS study were recorded in kilograms and reported to the nearest 0.5 kilograms. Data were reported in both kilograms and pounds ( $1 \mathrm{~kg}=2.20$ pounds).

\section{RESULTS}

A total of 2,582 men and 3,684 women provided data for grip strength measurement. The means and standard deviations for age, stratified by five-year intervals, are provided in Table 1. Means, standard deviations, and sample size for grip strength (in kilograms and pounds) stratified by 5 years and according to subjects' sex are found in Tables 2 and 3 . Percentile ranks were calculated using the means and standard deviations. Percentile ranks for grip strength, stratified according to subjects' sex and age group can be found in Appendices 1 through 8. Percentile rank values for both men and women exhibited no overlap when expressed in pounds. Percentile rank values for the left hand in men between 85 and 89 years old overlapped across the 45th and 50th percentiles when expressed as kilograms (see Appendix 2). The percentile rank tables for women (measured in kilograms) demonstrated overlap across several age groups (Appendices 5 and 6).

\section{DISCUSSION}


As reported previously, grip strength decreases with age in both men and women. ${ }^{13-15}$ Decreased maximum grip strength is associated with limitations in a number of activities, including heavy housework, walking, climbing stairs, and lifting objects in older adults. ${ }^{9}$ Over the last 2 decades, grip strength has been touted as a simple and convenient measure to screen an individual's strength and to monitor changes over time. ${ }^{15,18-20}$ It has been used as an indicator of frailty in adults over the age of 65 years ${ }^{12}$ and older and oncology patients. ${ }^{10,11}$ It may be predictive of future health, 19 including all-cause death, cardiovascular death, and cardiovascular disease. ${ }^{4}$

Mathiowetz et al developed normative data for grip strength in 1985 for individuals between the ages of 20 years and 94 years. ${ }^{5}$ These data have been used in the instruction manuals for several prominent hand-held dynamometers, including the Jamar dynamometer and the Lafayette dynamometer. 21 However, Mathiowetz et al employed a sample size of 628 volunteers. They divided the sample into 12 strata, which resulted in sample sizes between 21 and 29 subjects per stratum. ${ }^{5}$ They stratified their groups at five-year intervals, and all individuals over 75 years were combined into one stratum. These small sample sizes tend to yield unstable population estimates. The inclusion of all individuals over 75 into one group is ill-advised because there is considerable, uncaptured variability between 76 - and 90 -year-old patients. The normative data from the HRS reported in the current manuscript should provide more valid and current reference data about grip strength for clinicians.

Other reference values for grip strength have been published, but all suffer from inadequate sample sizes and/or strata, which are too wide to accurately capture the changes in grip strength, which occur quite rapidly with age. Budziareck et al provided grip strength data in dominant and non-dominant hands; however, their data were stratified using 30 -year intervals. ${ }^{22}$ Corish and Kennedy provided reference values for grip strength based on 276 men and 598 women between 65 and 85 years, using intervals of 5 years. ${ }^{23}$ Schlussel et al presented reference values for 1,122 men and 1,928 women, using strata widths of 10 years. 18 They categorized their subjects over the age of 70 years into one stratum. Luna-Heredia et al reported data for 229 men and 287 women, using strata of 10 years, and categorized their subjects over the age of 60 years into one stratum. 21 Hanten et al also provided reference values for grip strength using 553 men and 629 women in strata of 5 years, but the upper limit of their sample was 65 years. ${ }^{24}$ Werle et al provided reference values for grip strength for 507 men and 516 women between 20 years and greater than 85 years in strata of every 5 years, but the sample size in each stratum was low (ranging between 28 and 46 subjects). ${ }^{25}$ Jansen et al also reported reference values for grip strength in a small sample between 65 years and greater than 85 years in strata of 5 years. ${ }^{26}$ Finally, Spruit et al reported normative values from the United Kingdom for grip strength considering age, height, and measurement side in 102,972 men and 121,858 women between 39 and 73 years, using five-year strata. ${ }^{27}$ However, they categorized all subjects over 65 years into one stratum.

Gunther et al reported correlations between grip strength and factors, such as weight, height, body mass index, forearm length, forearm circumference, hand width, hand length, and hand circumference. 28 Several of the relationships were reported to be significant (ie the relationship was not equal to 0 ). However, the coefficients of determination between grip strength and these factors were quite low; only a small amount of the variability in grip strength can be accounted for by any one of these factors.

Anakwe et al maintained that both age and sex were important in determining maximum grip strength measurements. ${ }^{29}$ Their data showed that grip strength declines as an individual ages. Further, men show a greater decline than women. For both men and women, the right hand produces a greater mean grip strength measurement than the left hand in all age groups. Therefore, we have stratified our groups by age, sex, and handedness.

For data collected in the HRS study reported herein, the mean grip strength for two trials was used. Grip strength tends to decrease from the first to the third measurement in both men and women. 30 Using the mean of the first two measures may decrease the influence of fatigue. However, using the mean of two trials may have provided some difficulty in calculating the percentile ranks. We found some instances of overlap in percentile ranks. It is recommended that units of pounds be used as it is easier to discriminate between percentile ranks.

Challenges exist when comparing this study to the currently accepted normative values. Data were analyzed based on the Smedley-type dynamometer, whereas Mathiowetz et al used the Jamar dynamometer (Lafayette Instrument Co, Lafayette, IN). Innes reported that the Smedley dynamometer has excellent test-retest reliability similar to that of the Jamar dynamometer. ${ }^{30}$ Therefore, clinicians should exercise caution when using a dynamometer other than the Smedley.

This testing position also differs from the one used by Matiowetz et al. ${ }^{5}$ The standard testing position is seated with shoulder adducted and elbow flexed to $90^{\circ}$. The subjects in the HRS study were asked to stand with shoulder adducted and elbow flexed to $90^{\circ}$. If subjects were unable to maintain standing, they were permitted to complete the test either seated or in a supine position,

(C) The Internet Journal of Allied Health Sciences and Practice, 2018 
but they maintained shoulder adduction and elbow flexion to $90^{\circ}$. Amosun et al reported that a standing position produced a higher grip strength measurement. ${ }^{31}$ Further investigation is needed to determine if these reference values can be applied to individuals with comorbidities who are unable to stand during the test.

With the sample sizes for each of the hand grip estimates reported in the current study, we were $99 \%$ confident that the true population mean was within a half-width of 5 pounds with two exceptions: men between 50 and 54 years and men between 85 and 89 years. The sample size required to achieve $99 \%$ confidence \pm 5 pounds was 57 , and our sample was 44 . For men 85 to 89 years, the sample size required for our confidence interval was 189 , and the HRS data provided 139. Caution should be exercised when interpreting the estimates for these two, underrepresented groups.

\section{CONCLUSION}

Assessment of grip strength may be underutilized in the physical therapy setting, 32 which may be due to the lack of clinician knowledge, accessibility to hand dynamometers, or minimal statistical support for the current normative values. There have been no normative values developed with large sample sizes. Studies have been completed regarding testing position, validity and reliability of specific hand dynamometers, and an individual's overall strength when compared with grip strength, but research regarding a single individual's grip strength compared with population values is minimal. Through this study, reference values with a large sample size can be used in a clinical setting to provide an alternative to the reference values from the Matiowetz et al. 5 The HRS data were used to develop means, standard deviations, and percentile ranks for individuals between the ages of 50 and 89 years old, stratified by five-year age groups and sex. As clinical practice continues to advance and the population continues to age, we need to incorporate an array of objective measures that are reliable, convenient, and efficient for screening. Grip strength provides a comprehensive physical assessment that can be completed within one minute. With the development of normative values, clinicians are now able to use grip strength in their clinical practice and provide their patients/clients with information and data illustrating how their strength compares with that of other individuals similar in age and of the same sex. 
TABLE 1. Means and Standard Deviation for Age According to Stratum and Sex

\begin{tabular}{|c|c|c|c|c|}
\hline Age (yrs) & Sex & Mean & $S D \pm$ & $n$ \\
\hline \multirow[t]{2}{*}{50 to 54} & Male & 52.26 & 1.45 & 44 \\
\hline & Female & 52.46 & 1.35 & 197 \\
\hline \multirow[t]{2}{*}{55 to 59} & Male & 57.01 & 1.39 & 411 \\
\hline & Female & 56.99 & 1.46 & 550 \\
\hline \multirow[t]{2}{*}{60 to 64} & Male & 61.80 & 1.35 & 317 \\
\hline & Female & 61.93 & 1.42 & 515 \\
\hline \multirow[t]{2}{*}{65 to 69} & Male & 67.37 & 1.35 & 474 \\
\hline & Female & 67.13 & 1.37 & 681 \\
\hline \multirow[t]{2}{*}{70 to 74} & Male & 71.85 & 1.40 & 518 \\
\hline & Female & 71.92 & 1.43 & 706 \\
\hline \multirow[t]{2}{*}{75 to 79} & Male & 76.91 & 1.33 & 413 \\
\hline & Female & 76.91 & 1.39 & 506 \\
\hline \multirow[t]{2}{*}{80 to 84} & Male & 81.86 & 1.40 & 266 \\
\hline & Female & 81.90 & 1.40 & 309 \\
\hline \multirow[t]{2}{*}{85 to 89} & Male & 86.66 & 1.34 & 139 \\
\hline & Female & 86.78 & 1.39 & 220 \\
\hline \multirow[t]{2}{*}{ TOTAL } & Male & 69.73 & 9.00 & 2582 \\
\hline & Female & 68.84 & 9.41 & 3684 \\
\hline
\end{tabular}

$\pm S D=$ standard deviation 
TABLE 2. Means and Standard Deviations for Grip Strength $(\mathrm{kg})$ According to Age and Sex

\begin{tabular}{|c|c|c|c|c|c|}
\hline Age (yrs) & Hand & Mean & $S D \pm$ & Mean & $S D \pm$ \\
\hline \multirow{2}{*}{50 to 54} & \multirow{2}{*}{$\begin{array}{c}\text { Right } \\
\text { Left }\end{array}$} & 44.72 & 9.60 & 28.19 & 6.29 \\
\hline & & 42.22 & 9.75 & 25.56 & 5.60 \\
\hline \multirow{2}{*}{55 to 59} & \multirow{2}{*}{$\begin{array}{l}\text { Right } \\
\text { Left }\end{array}$} & 44.89 & 9.20 & 26.90 & 6.33 \\
\hline & & 40.86 & 8.72 & 24.34 & 5.61 \\
\hline \multirow{2}{*}{60 to 64} & \multirow{2}{*}{$\begin{array}{l}\text { Right } \\
\text { Left }\end{array}$} & 42.10 & 9.99 & 25.58 & 6.08 \\
\hline & & 39.32 & 9.00 & 23.05 & 5.55 \\
\hline \multirow{2}{*}{65 to 69} & \multirow{2}{*}{$\begin{array}{c}\text { Right } \\
\text { Left }\end{array}$} & 40.00 & 8.28 & 24.17 & 5.97 \\
\hline & & 36.39 & 7.81 & 21.62 & 5.16 \\
\hline \multirow{2}{*}{70 to 74} & \multirow{2}{*}{$\begin{array}{c}\text { Right } \\
\text { Left }\end{array}$} & 36.90 & 8.45 & 23.01 & 5.59 \\
\hline & & 34.39 & 7.77 & 20.58 & 9.29 \\
\hline \multirow{2}{*}{75 to 79} & \multirow{2}{*}{$\begin{array}{l}\text { Right } \\
\text { Left }\end{array}$} & 34.27 & 7.94 & 20.91 & 5.36 \\
\hline & & 31.36 & 7.38 & 18.49 & 4.95 \\
\hline \multirow{2}{*}{80 to 84} & \multirow{2}{*}{$\begin{array}{l}\text { Right } \\
\text { Left }\end{array}$} & 30.35 & 8.07 & 18.87 & 4.76 \\
\hline & & 27.84 & 7.35 & 16.73 & 4.21 \\
\hline \multirow{2}{*}{85 to 89} & \multirow{2}{*}{$\begin{array}{l}\text { Right } \\
\text { Left }\end{array}$} & 28.41 & 7.95 & 16.93 & 4.46 \\
\hline & & 25.49 & 7.20 & 15.22 & 4.77 \\
\hline
\end{tabular}

$\pm S D=$ standard deviation 
TABLE 3. Means and Standard Deviations for Grip Strength (Pounds) According to Age and Sex Men

Women

\begin{tabular}{|c|c|c|c|c|c|}
\hline Age (yrs) & Hand & Mean & $S D_{ \pm}$ & Mean & $S D_{ \pm}$ \\
\hline \multirow{2}{*}{50 to 54} & \multirow{2}{*}{$\begin{array}{l}\text { Right } \\
\text { Left }\end{array}$} & 98.59 & 21.16 & 62.16 & 13.87 \\
\hline & & 93.07 & 21.49 & 56.35 & 12.34 \\
\hline \multirow{2}{*}{55 to 59} & \multirow{2}{*}{$\begin{array}{l}\text { Right } \\
\text { Left }\end{array}$} & 98.96 & 20.28 & 59.31 & 13.96 \\
\hline & & 90.08 & 19.21 & 53.66 & 12.37 \\
\hline \multirow{2}{*}{60 to 64} & \multirow{2}{*}{$\begin{array}{l}\text { Right } \\
\text { Left }\end{array}$} & 92.81 & 22.02 & 56.38 & 13.41 \\
\hline & & 86.69 & 19.84 & 50.82 & 12.23 \\
\hline \multirow{2}{*}{65 to 69} & \multirow{2}{*}{$\begin{array}{l}\text { Right } \\
\text { Left }\end{array}$} & 88.18 & 18.25 & 53.29 & 13.16 \\
\hline & & 80.23 & 17.21 & 47.67 & 11.37 \\
\hline \multirow{2}{*}{70 to 74} & \multirow{2}{*}{$\begin{array}{l}\text { Right } \\
\text { Left }\end{array}$} & 81.36 & 18.63 & 50.72 & 12.32 \\
\hline & & 75.81 & 17.14 & 45.36 & 10.89 \\
\hline \multirow{2}{*}{75 to 79} & \multirow{2}{*}{$\begin{array}{l}\text { Right } \\
\text { Left }\end{array}$} & 75.55 & 17.51 & 46.11 & 11.81 \\
\hline & & 69.13 & 16.27 & 40.77 & 10.90 \\
\hline \multirow{2}{*}{80 to 84} & \multirow{2}{*}{$\begin{array}{l}\text { Right } \\
\text { Left }\end{array}$} & 66.91 & 17.79 & 41.60 & 10.49 \\
\hline & & 61.38 & 16.20 & 36.88 & 9.28 \\
\hline \multirow{2}{*}{85 to 89} & \multirow{2}{*}{$\begin{array}{c}\text { Right } \\
\text { Left }\end{array}$} & 62.63 & 17.52 & 37.33 & 10.19 \\
\hline & & 56.21 & 15.87 & 33.56 & 10.51 \\
\hline
\end{tabular}

$\pm S D=$ standard deviation 


\section{REFERENCES:}

1. Gale CR, Martyn CN, Cooper C, Sayer AA. Grip strength, body composition, and mortality. Int J Epidemiol. 2007 Feb;36(1):228-35. Epub 2006 Oct 19. [PMID: 17056604]

2. Rantanen $T$, Volpato S, Ferrucci L, Heikkinen E, Fried LP, et al. Handgrip strength and cause-specific and total mortality in older disabled women: exploring the mechanism. J Am Geriatr Soc. 2003 May;51(5):636-41. [PMID: 12752838]

3. Simmonds SJ, Syddall HE, Westbury LD, Dodds RM, Cooper C, et al. Grip strength among community-dwelling older people predicts hospital admission during the following decade. Age Ageing. 2015 Nov;44(6):954-9. [PMID: 26504117]

4. Leong DP, Teo KK, Rangarajan S, Lopez-Jaramillo P, Avezum A Jr, et al. Prospective Urban Rural Epidemiology (PURE) Study investigators. Prognostic value of grip strength: findings from the Prospective Urban Rural Epidemiology (PURE) study. Lancet. 2015 Jul 18;386(9990):266-73. [PMID: 25982160]

5. Mathiowetz V, Kashman N, Volland G, Weber K, Dowe M, et al. Grip and pinch strength: normative data for adults. Arch Phys Med Rehabil. 1985 Feb;66(2):69-74. [PMID: 3970660]

6. Health and Retirement Study, 2008 public use dataset. Produced and distributed by the University of Michigan with funding from the National Institute on Aging (grant number NIA U01AG009740). Ann Arbor, MI, 2014.

7. Guerra RS, Amaral TF. Comparison of hand dynamometers in elderly people. J Nutr Health Aging. 2009 Dec;13(10):907-12. [PMID: 19924352]

8. Howell D. Statistical Methods for Psychology. Boston, MA: Duxbury Press; 1982.

9. Rantanen T, Guralnik JM, Foley D, Masaki K, Leveille S, et al. Midlife hand grip strength as a predictor of old age disability. JAMA. 1999 Feb 10;281(6):558-60. [PMID: 10022113]

10. Farcet A, de Decker L, Pauly V, Rousseau F, Bergman H, Molines C, Retornaz F. Frailty Markers and Treatment Decisions in Patients Seen in Oncogeriatric Clinics: Results from the ASRO Pilot Study. PLoS One. 2016 Feb 26;11(2):e0149732. [PubMed PMID: 26918947]

11. Retornaz F, Monette J, Batist G, Monette M, Sourial N, Small D, Caplan S, Wan-Chow-Wah D, Puts MT, Bergman H. Usefulness of frailty markers in the assessment of the health and functional status of older cancer patients referred for chemotherapy: a pilot study. J Gerontol A Biol Sci Med Sci. 2008 May;63(5):518-22. [PMID: 18511757]

12. Woo J, Yu R, Wong M, Yeung F, Wong M, Lum C. Frailty Screening in the Community Using the FRAIL Scale. J Am Med Dir Assoc. 2015 May 1;16(5):412-9. [PMID: 25732832]

13. Frederiksen H, Hjelmborg J, Mortensen J, McGue M, Vaupel JW, Christensen K. Age trajectories of grip strength: crosssectional and longitudinal data among 8,342 Danes aged 46 to 102. Ann Epidemiol. 2006 Jul;16(7):554-62. [PMID: 16406245]

14. Vaz M, Hunsberger S, Diffey B. Prediction equations for handgrip strength in healthy Indian male and female subjects encompassing a wide age range. Ann Hum Biol. 2002 Mar-Apr;29(2):131-41. [PMID: 11874620]

15. Lino VT, Rodrigues NC, O'Dwyer G, Andrade MK, Mattos IE, et al. Handgrip Strength and Factors Associated in Poor Elderly Assisted at a Primary Care Unit in Rio de Janeiro, Brazil. PLoS One. 2016 Nov 10;11(11):e0166373. [PMID: 27832209]

16. Bohannon RW. Grip strength: a summary of studies comparing dominant and nondominant limb measurements. Percept Mot Skills. 2003 Jun;96(3 Pt 1):728-30. Review. [PMID: 12831245]

17. Thorpe RJ, Simonsick E, Zonderman A, Evans MK. Association between Race, Household Income and Grip Strength in Middle- and Older-Aged Adults. Ethn Dis. 2016 Oct 20;26(4):493-500. [PubMed PMID: 27773976]

18. Schlüssel MM, dos Anjos LA, de Vasconcellos MT, Kac G. Reference values of handgrip dynamometry of healthy adults: a population-based study. Clin Nutr. 2008 Aug;27(4):601-7. [PMID: 18547686]

19. Kerr A, Syddall HE, Cooper C, Turner GF, Briggs RS, Sayer AA. Does admission grip strength predict length of stay in hospitalised older patients? Age Ageing. 2006 Jan;35(1):82-4. [PMID: 16364940]

20. Li K, Hewson DJ, Duchêne J, Hogrel JY. Predicting maximal grip strength using hand circumference. Man Ther. 2010 Dec;15(6):579-85. [PMID: 20708427]

21. Luna-Heredia E, Martín-Peña G, Ruiz-Galiana J. Handgrip dynamometry in healthy adults. Clin Nutr. 2005 Apr;24(2):250-8. [PMID: 15784486]

22. Budziareck MB, Pureza Duarte RR, Barbosa-Silva MC. Reference values and determinants for handgrip strength in healthy subjects. Clin Nutr. 2008 Jun;27(3):357-62. [PMID: 18455840]

(c) The Internet Journal of Allied Health Sciences and Practice, 2018 
23. Corish CA, Kennedy NP. Anthropometric measurements from a cross-sectional survey of Irish free-living elderly subjects with smoothed centile curves. Br J Nutr. 2003 Jan;89(1):137-45. [PMID: 12568673]

24. Hanten WP, Chen WY, Austin AA, Brooks RE, Carter HC, et al. Maximum grip strength in normal subjects from 20 to 64 years of age. J Hand Ther. 1999 Jul-Sep;12(3):193-200. [PMID: 10459527]

25. Werle S, Goldhahn J, Drerup S, Simmen BR, Sprott H, Herren DB. Age- and gender-specific normative data of grip and pinch strength in a healthy adult Swiss population. J Hand Surg Eur Vol. 2009 Feb;34(1):76-84. [PMID: 19129352]

26. Jansen CW, Niebuhr BR, Coussirat DJ, Hawthorne D, Moreno L, et al. Hand force of men and women over 65 years of age as measured by maximum pinch and grip force. J Aging Phys Act. 2008 Jan;16(1):24-41. [PMID: 18212392]

27. Spruit MA, Sillen MJ, Groenen MT, Wouters EF, Franssen FM. New normative values for handgrip strength: results from the UK Biobank. J Am Med Dir Assoc. 2013 Oct;14(10):775.e5-11. [PMID: 23958225]

28. Günther CM, Bürger A, Rickert M, Crispin A, Schulz CU. Grip strength in healthy caucasian adults: reference values. J Hand Surg Am. 2008 Apr;33(4):558-65. [PMID: 18406961]

29. Anakwe RE, Huntley JS, McEachan JE. Grip strength and forearm circumference in a healthy population. J Hand Surg Eur Vol. 2007;32(2):203-9.

30. Innes E. Handgrip strength testing: A review of the literature. Aust Occup Ther J.1999;46(3):120-40.

31. Amosun S, Moyo A, Matara C. Trends in hand grip strength in some adult male Zimbabweans. Br J Occup Ther. 1995;58(8):345-8.

32. García-Peña C, García-Fabela LC, Gutiérrez-Robledo LM, García-González JJ, Arango-Lopera VE, Pérez-Zepeda MU. Handgrip strength predicts functional decline at discharge in hospitalized male elderly: a hospital cohort study. PLoS One. 2013 Jul 25;8(7):e69849. [PMID: 23936113] 
APPENDIX 1. Percentile Ranks for Men-Right Hand (kg)

\section{Age Stratum}

\begin{tabular}{ccccccccc}
$\begin{array}{c}\text { Percentile } \\
\text { rank }\end{array}$ & $\mathbf{5 0}$ to & $\mathbf{5 5}$ to & $\mathbf{6 0}$ to & $\mathbf{6 5}$ to & $\mathbf{7 0}$ to & $\mathbf{7 5}$ to & $\mathbf{8 0}$ to & $\mathbf{8 5}$ to \\
\hline 95 & $\mathbf{5 4}$ & $\mathbf{5 9}$ & $\mathbf{6 4}$ & $\mathbf{6 9}$ & $\mathbf{7 4}$ & $\mathbf{7 9}$ & $\mathbf{8 4}$ & $\mathbf{8 9}$ \\
\hline 90 & 61 & 60 & 59 & 52 & 51 & 47 & 44 & 41 \\
85 & 57 & 57 & 55 & 49 & 48 & 44 & 41 & 39 \\
80 & 55 & 54 & 52 & 47 & 46 & 43 & 39 & 37 \\
75 & 53 & 53 & 51 & 45 & 44 & 41 & 37 & 35 \\
70 & 51 & 51 & 49 & 44 & 43 & 40 & 36 & 34 \\
65 & 50 & 50 & 47 & 42 & 41 & 38 & 35 & 33 \\
60 & 48 & 48 & 46 & 41 & 40 & 37 & 33 & 31 \\
55 & 47 & 47 & 45 & 40 & 39 & 36 & 32 & 30 \\
50 & 46 & 46 & 43 & 39 & 38 & 35 & 31 & 29 \\
45 & 45 & 45 & 42 & 38 & 37 & 34 & 30 & 28 \\
40 & 44 & 44 & 41 & 37 & 36 & 33 & 29 & 27 \\
35 & 42 & 43 & 40 & 36 & 35 & 32 & 28 & 26 \\
30 & 41 & 41 & 38 & 35 & 34 & 31 & 27 & 25 \\
25 & 40 & 40 & 37 & 34 & 32 & 30 & 26 & 24 \\
20 & 38 & 39 & 35 & 32 & 31 & 29 & 25 & 23 \\
15 & 37 & 37 & 34 & 31 & 30 & 28 & 24 & 22 \\
10 & 35 & 35 & 32 & 29 & 28 & 26 & 22 & 20 \\
5 & 32 & 33 & 29 & 27 & 26 & 24 & 20 & 18 \\
\hline
\end{tabular}


APPENDIX 2. Percentile Ranks for Men-Left Hand (kg)

\begin{tabular}{|c|c|c|c|c|c|c|c|c|}
\hline \multicolumn{9}{|c|}{ Age Stratum } \\
\hline Percentile & & & & & & & & \\
\hline rank & $\begin{array}{c}50 \text { to } \\
54\end{array}$ & $\begin{array}{c}55 \text { to } \\
59\end{array}$ & $\begin{array}{c}60 \text { to } \\
64\end{array}$ & $\begin{array}{c}65 \text { to } \\
69\end{array}$ & $\begin{array}{c}70 \text { to } \\
74\end{array}$ & $\begin{array}{c}75 \text { to } \\
79\end{array}$ & $\begin{array}{c}80 \text { to } \\
84\end{array}$ & $\begin{array}{c}85 \text { to } \\
89\end{array}$ \\
\hline 95 & 58 & 55 & 54 & 39 & 47 & 43 & 40 & 37 \\
\hline 90 & 55 & 52 & 51 & 36 & 44 & 41 & 37 & 35 \\
\hline 85 & 52 & 50 & 49 & 34 & 42 & 39 & 35 & 33 \\
\hline 80 & 50 & 48 & 47 & 33 & 41 & 38 & 34 & 32 \\
\hline 75 & 49 & 47 & 45 & 32 & 40 & 36 & 33 & 30 \\
\hline 70 & 47 & 45 & 44 & 30 & 38 & 35 & 32 & 29 \\
\hline 65 & 46 & 44 & 43 & 29 & 37 & 34 & 31 & 28 \\
\hline 60 & 45 & 43 & 42 & 28 & 36 & 33 & 30 & 27 \\
\hline 55 & 43 & 42 & 40 & 27 & 35 & 32 & 29 & 26 \\
\hline 50 & 42 & 41 & 39 & 26 & 34 & 31 & 28 & 25 \\
\hline 45 & 41 & 40 & 38 & 25 & 33 & 30 & 27 & 25 \\
\hline 40 & 40 & 39 & 37 & 24 & 32 & 29 & 26 & 24 \\
\hline 35 & 38 & 38 & 36 & 23 & 31 & 29 & 25 & 23 \\
\hline 30 & 37 & 36 & 35 & 22 & 30 & 27 & 24 & 22 \\
\hline 25 & 36 & 35 & 33 & 21 & 29 & 26 & 23 & 21 \\
\hline 20 & 34 & 34 & 32 & 20 & 28 & 25 & 22 & 19 \\
\hline 15 & 32 & 32 & 30 & 18 & 26 & 24 & 20 & 18 \\
\hline 10 & 30 & 30 & 28 & 16 & 24 & 22 & 18 & 16 \\
\hline 5 & 26 & 27 & 25 & 13 & 22 & 19 & 16 & 14 \\
\hline
\end{tabular}


APPENDIX 3. Percentile Ranks for Men-Right Hand (Pounds)

\begin{tabular}{|c|c|c|c|c|c|c|c|c|}
\hline \multirow{2}{*}{$\begin{array}{l}\text { Percentile } \\
\text { rank }\end{array}$} & \multicolumn{8}{|c|}{ Age Stratum } \\
\hline & $\begin{array}{l}50 \text { to } \\
54\end{array}$ & $\begin{array}{c}55 \text { to } \\
59\end{array}$ & $\begin{array}{c}60 \text { to } \\
64\end{array}$ & 65 to 69 & $\begin{array}{l}70 \text { to } \\
74\end{array}$ & $\begin{array}{c}75 \text { to } \\
79\end{array}$ & $\begin{array}{l}80 \text { to } \\
84\end{array}$ & $\begin{array}{c}85 \text { to } \\
89\end{array}$ \\
\hline 95 & 133 & 132 & 129 & 118 & 112 & 104 & 96 & 91 \\
\hline 90 & 126 & 125 & 121 & 112 & 105 & 98 & 90 & 85 \\
\hline 85 & 121 & 120 & 116 & 107 & 101 & 94 & 85 & 81 \\
\hline 80 & 116 & 116 & 111 & 104 & 97 & 90 & 82 & 77 \\
\hline 75 & 113 & 113 & 108 & 100 & 94 & 87 & 79 & 74 \\
\hline 70 & 110 & 110 & 104 & 98 & 91 & 85 & 76 & 72 \\
\hline 65 & 107 & 107 & 101 & 95 & 89 & 82 & 74 & 69 \\
\hline 60 & 104 & 104 & 98 & 93 & 86 & 80 & 71 & 67 \\
\hline 55 & 101 & 102 & 96 & 90 & 84 & 78 & 69 & 65 \\
\hline 50 & 99 & 99 & 93 & 88 & 81 & 76 & 67 & 63 \\
\hline 45 & 96 & 96 & 90 & 86 & 79 & 73 & 65 & 60 \\
\hline 40 & 93 & 94 & 87 & 84 & 77 & 71 & 62 & 58 \\
\hline 35 & 90 & 91 & 84 & 81 & 74 & 69 & 60 & 56 \\
\hline 30 & 87 & 88 & 81 & 79 & 72 & 66 & 58 & 53 \\
\hline 25 & 84 & 85 & 78 & 76 & 69 & 64 & 55 & 51 \\
\hline 20 & 81 & 82 & 74 & 73 & 66 & 61 & 52 & 48 \\
\hline 15 & 77 & 78 & 70 & 69 & 62 & 57 & 48 & 44 \\
\hline 10 & 71 & 73 & 65 & 65 & 57 & 53 & 44 & 40 \\
\hline 5 & 64 & 66 & 57 & 58 & 51 & 47 & 38 & 34 \\
\hline
\end{tabular}


APPENDIX 4. Percentile Ranks for Men-Left Hand (Pounds)

\begin{tabular}{ccccccccc}
\hline $\begin{array}{c}\text { Percentile } \\
\text { rank }\end{array}$ & $\mathbf{5 0}$ to & $\mathbf{5 5}$ to & $\mathbf{6 0}$ to & $\mathbf{6 5}$ to $\mathbf{6 9}$ & $\mathbf{7 0}$ to & $\mathbf{7 5 \text { to }}$ & $\mathbf{8 0}$ to & $\mathbf{8 5}$ to \\
\hline 95 & $\mathbf{5 4}$ & $\mathbf{5 9}$ & $\mathbf{6 4}$ & & $\mathbf{7 4}$ & $\mathbf{7 9}$ & $\mathbf{8 4}$ & $\mathbf{8 9}$ \\
\hline 90 & 128 & 122 & 119 & 109 & 104 & 96 & 88 & 82 \\
85 & 121 & 115 & 112 & 102 & 98 & 90 & 82 & 77 \\
80 & 115 & 110 & 107 & 98 & 94 & 86 & 78 & 73 \\
75 & 111 & 106 & 103 & 95 & 90 & 83 & 75 & 70 \\
70 & 108 & 103 & 100 & 92 & 87 & 80 & 72 & 67 \\
65 & 104 & 100 & 97 & 89 & 85 & 78 & 70 & 65 \\
60 & 101 & 97 & 94 & 87 & 82 & 75 & 68 & 62 \\
55 & 99 & 95 & 92 & 85 & 80 & 73 & 65 & 60 \\
50 & 96 & 92 & 89 & 82 & 78 & 71 & 63 & 58 \\
45 & 93 & 90 & 87 & 80 & 76 & 69 & 61 & 56 \\
40 & 90 & 88 & 84 & 78 & 74 & 67 & 59 & 54 \\
35 & 88 & 85 & 82 & 76 & 71 & 65 & 57 & 52 \\
30 & 85 & 83 & 79 & 74 & 69 & 63 & 55 & 50 \\
25 & 82 & 80 & 76 & 71 & 67 & 61 & 53 & 48 \\
20 & 79 & 77 & 73 & 69 & 64 & 58 & 50 & 45 \\
15 & 75 & 74 & 70 & 66 & 61 & 55 & 48 & 43 \\
10 & 71 & 70 & 66 & 62 & 58 & 52 & 45 & 40 \\
5 & 66 & 65 & 61 & 58 & 54 & 48 & 41 & 36 \\
\hline 5 & 58 & 58 & 54 & 52 & 48 & 42 & 35 & 30 \\
\hline
\end{tabular}


APPENDIX E. Percentile Ranks for Women-Right Hand (kg)

\begin{tabular}{ccccccccc}
\hline $\begin{array}{c}\text { Percentile } \\
\text { rank }\end{array}$ & $\mathbf{5 0}$ to & $\mathbf{5 5}$ to & $\mathbf{6 0}$ to & $\mathbf{6 5}$ to $\mathbf{6 9}$ & $\mathbf{7 0}$ to & $\mathbf{7 5}$ to & $\mathbf{8 0}$ to & $\mathbf{8 5}$ to \\
\hline 95 & $\mathbf{5 4}$ & $\mathbf{5 9}$ & $\mathbf{6 4}$ & & $\mathbf{7 4}$ & $\mathbf{7 9}$ & $\mathbf{8 4}$ & $\mathbf{8 9}$ \\
\hline 90 & 39 & 37 & 36 & 34 & 32 & 30 & 27 & 25 \\
85 & 36 & 35 & 33 & 32 & 30 & 28 & 25 & 23 \\
80 & 35 & 33 & 32 & 30 & 29 & 26 & 24 & 22 \\
75 & 33 & 32 & 31 & 29 & 28 & 25 & 23 & 21 \\
70 & 32 & 31 & 30 & 28 & 27 & 25 & 22 & 20 \\
65 & 31 & 30 & 29 & 27 & 26 & 24 & 21 & 19 \\
60 & 31 & 29 & 28 & 26 & 25 & 23 & 21 & 19 \\
55 & 30 & 29 & 27 & 26 & 24 & 22 & 20 & 18 \\
50 & 29 & 28 & 26 & 25 & 24 & 22 & 19 & 18 \\
45 & 28 & 27 & 26 & 24 & 23 & 21 & 19 & 17 \\
40 & 27 & 26 & 25 & 23 & 22 & 20 & 18 & 16 \\
35 & 27 & 25 & 24 & 23 & 22 & 20 & 18 & 16 \\
30 & 26 & 24 & 23 & 22 & 21 & 19 & 17 & 15 \\
25 & 25 & 24 & 22 & 21 & 20 & 18 & 16 & 15 \\
20 & 24 & 23 & 21 & 20 & 19 & 17 & 16 & 14 \\
15 & 23 & 22 & 20 & 19 & 18 & 16 & 15 & 13 \\
10 & 22 & 20 & 19 & 18 & 17 & 15 & 14 & 12 \\
5 & 20 & 19 & 18 & 17 & 16 & 14 & 13 & 11 \\
\hline 5 & 18 & 16 & 16 & 14 & 14 & 12 & 11 & 9 \\
\hline
\end{tabular}


APPENDIX 5. Percentile Ranks for Women-Left Hand (kg)

\begin{tabular}{ccccccccc}
\hline $\begin{array}{c}\text { Percentile } \\
\text { rank }\end{array}$ & $\mathbf{5 0}$ to & $\mathbf{5 5}$ to & $\mathbf{6 0}$ to & $\mathbf{6 5}$ to & $\mathbf{7 0}$ to & $\mathbf{7 5}$ to & $\mathbf{8 0}$ to & $\mathbf{8 5}$ to \\
\hline 95 & $\mathbf{5 4}$ & $\mathbf{5 9}$ & $\mathbf{6 4}$ & $\mathbf{6 9}$ & $\mathbf{7 4}$ & $\mathbf{7 9}$ & $\mathbf{8 4}$ & $\mathbf{8 9}$ \\
\hline 90 & 35 & 34 & 32 & 30 & 29 & 27 & 24 & 23 \\
85 & 33 & 32 & 30 & 28 & 27 & 25 & 22 & 21 \\
80 & 31 & 30 & 29 & 27 & 26 & 24 & 21 & 20 \\
75 & 30 & 29 & 28 & 26 & 25 & 23 & 20 & 19 \\
70 & 29 & 28 & 27 & 25 & 24 & 22 & 20 & 18 \\
65 & 28 & 27 & 26 & 24 & 23 & 21 & 19 & 18 \\
60 & 28 & 27 & 25 & 24 & 22 & 20 & 18 & 17 \\
55 & 27 & 26 & 24 & 23 & 22 & 20 & 18 & 16 \\
50 & 26 & 25 & 24 & 22 & 21 & 19 & 17 & 16 \\
45 & 26 & 24 & 23 & 22 & 21 & 18 & 17 & 15 \\
40 & 25 & 24 & 22 & 21 & 20 & 18 & 16 & 15 \\
35 & 24 & 23 & 22 & 20 & 19 & 17 & 16 & 14 \\
30 & 23 & 22 & 21 & 20 & 19 & 17 & 15 & 13 \\
25 & 23 & 21 & 20 & 19 & 18 & 16 & 15 & 13 \\
20 & 22 & 21 & 19 & 18 & 17 & 15 & 14 & 12 \\
15 & 21 & 20 & 18 & 17 & 16 & 14 & 13 & 11 \\
10 & 20 & 19 & 17 & 16 & 15 & 13 & 12 & 10 \\
5 & 18 & 17 & 16 & 15 & 14 & 12 & 11 & 9 \\
\hline 0 & 16 & 15 & 14 & 13 & 12 & 10 & 10 & 7 \\
\hline
\end{tabular}


APPENDIX 6. Percentile Ranks for Women-Right Hand (Pounds)

\begin{tabular}{ccccccccc}
\hline $\begin{array}{c}\text { Percentile } \\
\text { rank }\end{array}$ & $\mathbf{5 0}$ to & $\mathbf{5 5}$ to & $\mathbf{6 0}$ to & $\mathbf{6 5}$ to $\mathbf{6 9}$ & $\mathbf{7 0}$ to & $\mathbf{7 5}$ to & $\mathbf{8 0}$ to & $\mathbf{8 5}$ to \\
\hline 95 & $\mathbf{5 4}$ & $\mathbf{5 9}$ & $\mathbf{6 4}$ & & $\mathbf{7 4}$ & $\mathbf{7 9}$ & $\mathbf{8 4}$ & $\mathbf{8 9}$ \\
\hline 90 & 85 & 82 & 78 & 75 & 71 & 66 & 59 & 54 \\
85 & 80 & 77 & 74 & 70 & 67 & 61 & 55 & 50 \\
80 & 77 & 74 & 70 & 67 & 63 & 58 & 52 & 48 \\
75 & 74 & 71 & 68 & 64 & 61 & 56 & 50 & 46 \\
70 & 72 & 69 & 65 & 62 & 59 & 54 & 49 & 44 \\
65 & 69 & 67 & 63 & 60 & 57 & 52 & 47 & 43 \\
60 & 68 & 65 & 62 & 58 & 55 & 51 & 46 & 41 \\
55 & 66 & 63 & 60 & 57 & 54 & 49 & 44 & 40 \\
50 & 64 & 61 & 58 & 55 & 52 & 48 & 43 & 39 \\
45 & 62 & 59 & 56 & 53 & 51 & 46 & 42 & 37 \\
40 & 60 & 58 & 55 & 52 & 49 & 45 & 40 & 36 \\
35 & 59 & 56 & 53 & 50 & 48 & 43 & 39 & 35 \\
30 & 57 & 54 & 51 & 48 & 46 & 42 & 38 & 33 \\
25 & 55 & 52 & 49 & 46 & 44 & 40 & 36 & 32 \\
20 & 53 & 50 & 47 & 44 & 42 & 38 & 35 & 30 \\
15 & 50 & 48 & 45 & 42 & 40 & 36 & 33 & 29 \\
10 & 48 & 45 & 42 & 40 & 38 & 34 & 31 & 27 \\
5 & 44 & 41 & 39 & 36 & 35 & 31 & 28 & 24 \\
\hline 0 & 39 & 36 & 34 & 32 & 30 & 27 & 24 & 21 \\
\hline
\end{tabular}


APPENDIX H. Percentile Ranks for Women-Left Hand (Pounds)

\begin{tabular}{ccccccccc}
\hline $\begin{array}{c}\text { Percentile } \\
\text { rank }\end{array}$ & $\mathbf{5 0}$ to & $\mathbf{5 5}$ to & $\mathbf{6 0}$ to & $\mathbf{6 5}$ to & $\mathbf{7 0}$ to & $\mathbf{7 5}$ to & $\mathbf{8 0}$ to & $\mathbf{8 5}$ to \\
\hline 95 & $\mathbf{5 4}$ & $\mathbf{5 9}$ & $\mathbf{6 4}$ & $\mathbf{6 9}$ & $\mathbf{7 4}$ & $\mathbf{7 9}$ & $\mathbf{8 4}$ & $\mathbf{8 9}$ \\
90 & 72 & 74 & 71 & 66 & 63 & 59 & 52 & 51 \\
85 & 70 & 66 & 62 & 59 & 55 & 49 & 47 \\
80 & 69 & 66 & 63 & 59 & 57 & 52 & 47 & 44 \\
75 & 67 & 64 & 61 & 57 & 55 & 50 & 45 & 42 \\
70 & 65 & 62 & 59 & 55 & 53 & 48 & 43 & 41 \\
65 & 63 & 60 & 57 & 54 & 51 & 46 & 42 & 39 \\
60 & 61 & 58 & 56 & 52 & 50 & 45 & 40 & 38 \\
55 & 59 & 57 & 54 & 51 & 48 & 44 & 39 & 36 \\
50 & 58 & 55 & 52 & 49 & 47 & 42 & 38 & 35 \\
45 & 56 & 54 & 51 & 48 & 45 & 41 & 37 & 34 \\
40 & 55 & 52 & 49 & 46 & 44 & 39 & 36 & 32 \\
35 & 53 & 51 & 48 & 45 & 43 & 38 & 35 & 31 \\
30 & 52 & 49 & 46 & 43 & 41 & 37 & 33 & 30 \\
25 & 50 & 47 & 44 & 42 & 40 & 35 & 32 & 28 \\
20 & 48 & 45 & 43 & 40 & 38 & 33 & 31 & 26 \\
15 & 46 & 43 & 41 & 38 & 36 & 32 & 29 & 25 \\
10 & 44 & 41 & 38 & 36 & 34 & 29 & 27 & 23 \\
5 & 41 & 38 & 35 & 33 & 31 & 27 & 25 & 20 \\
\hline
\end{tabular}

